This item was submitted to Loughborough's Research Repository by the author.

Items in Figshare are protected by copyright, with all rights reserved, unless otherwise indicated.

\title{
A cross-sectional study of physical activity and health-related quality of life in an elderly Indonesian cohort
}

PLEASE CITE THE PUBLISHED VERSION

http://dx.doi.org/10.4276/030802214X14098207541036

\section{PUBLISHER}

(c) The College of Occupational Therapists Ltd. Published by Sage.

\section{VERSION}

AM (Accepted Manuscript)

\section{PUBLISHER STATEMENT}

This work is made available according to the conditions of the Creative Commons Attribution-NonCommercialNoDerivatives 4.0 International (CC BY-NC-ND 4.0) licence. Full details of this licence are available at: https://creativecommons.org/licenses/by-nc-nd/4.0/

\section{LICENCE}

CC BY-NC-ND 4.0

\section{REPOSITORY RECORD}

Clifford, Angela, T.B. Rahardjo, Stephan Bandelow, and Eef Hogervorst. 2019. "A Cross-sectional Study of Physical Activity and Health-related Quality of Life in an Elderly Indonesian Cohort". figshare. https://hdl.handle.net/2134/25620. 


\title{
A cross-sectional study of physical activity and health-related quality of life in an elderly Indonesian cohort
}

\author{
Angela Clifford, ${ }^{1}$ Tri Budi Rahardjo, ${ }^{2}$ Stephan Bandelow, ${ }^{3}$ and Eef Hogervorst ${ }^{4}$
}

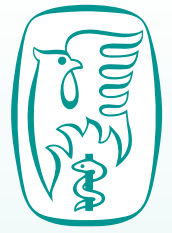

Key words:

Physical activity, quality of life, activities of daily living.

${ }^{1}$ Postdoctoral Researcher, Loughborough University, School of Sport, Exercise and Health Sciences, Loughborough.

2 Professor of Gerontology, University of Indonesia, Centre for Ageing Studies, Jakarta, Indonesia.

${ }^{3}$ Senior Lecturer, Loughborough University, School of Sport, Exercise and Health Sciences, Loughborough.

${ }^{4}$ Professor of Biological Psychiatry, Loughborough University, School of Sport, Exercise and Health Sciences, Loughborough.

Corresponding author: Prof Eef Hogervorst, Professor of Biological Psychiatry, Loughborough University, School of Sport, Exercise and Health Sciences, Loughborough. Email: e.hogervorst@|boro.ac.uk

Reference: Clifford A, Rahardjo TB, Bandelow S, Hogervorst E (2014) A cross-sectional study of physical activity and health-related quality of life in an elderly Indonesian cohort. British Journal of Occupational Therapy, 77(8), XXX-XXX.

DOI: TO BE INSERTED

(c) The College of Occupational Therapists Ltd. Submitted: 31 January 2011.

Accepted: 17 June 2014.
Introduction: Improving health-related Quality of Life (QoL) may have far reaching clinical implications, and previous studies have shown associations between participation in physical activity and higher QoL. However, it is unclear which types of physical activity are particularly beneficial and how much of this relationship is explained by Instrumental Activities of Daily Living (IADL) following physical activity.

Method: This observational study measured frequency of participation in several different physical activities and IADL scores in a large elderly, community-dwelling sample. Hierarchical regression analyses were used to assess relationships between these variables and self-rated QoL using the Medical Outcome Survey SF-36 questionnaire.

Findings: Participation in walking was found to be associated with higher QoL ratings in older men and women. IADL scores were correlated with QoL ratings but only partially mediated the association between walking and QoL. Participation in other types of physical activity was not significantly associated with QoL ratings.

Conclusion: Walking may be recommended alongside treatment for illness or disability due to its potential benefits to QoL and treatment outcomes. Further research should investigate the role of physical fitness in this relationship, to determine whether these findings can be replicated in different populations.

\section{Introduction}

Average life expectancy is increasing rapidly worldwide (World Health Organization 2011) and with this comes a higher rate of age-related illness and disability. Poor health has high social and economic costs, especially for long recovery or chronic disability. Health-related Quality of Life (QoL) is a measure of the physical, psychological, social and functional well-being of an individual (Fallowfield 2009, Hennesey et al 1994). QoL measures are increasingly used as prognostic indicators for a variety of conditions and are predictive of future hospitalization and mortality (Dorr et al 2006, Efficace et al 2006, Mapes et al 2003). They can also be used to aid the selection of treatment by balancing efficacy with side effects (Fallowfield 2009) that may contribute to relapse or require further care. Improving QoL in community samples may help to lower the demand on medical services and reduce the number of person years lost to illness and/or disability in the future. Assessing and improving QoL therefore offers possibly wide-reaching clinical implications.

Sedentary lifestyles are common in many parts of the world (van der Bij et al 2002), despite the fact that physical activity is often recommended in later life due to its benefits to cardiovascular and cognitive health (Clifford et al 2009, Houde and Melillo 2002). Physical activity has been associated previously with QoL in middle- to older-aged adults; Acree et al's (2010) cross-sectional study found that participation in regular physical activity was associated with increased QoL ratings in men and women aged around 70 years. Intervention studies have found similar results. For example, Cakar et al 
(2010) found that completing stretching, strength, and cardiovascular exercises 3 times a week for 6 weeks was associated with higher QoL for those in long-term care. In addition, men completing 6 months of structured aerobic activity showed higher QoL compared to a control group continuing their daily routine (Antunes et al 2005). Physical activity in general therefore appears to have positive effects on QoL.

It is unclear whether all types of physical activity have a positive effect on QoL. While Antunes et al (2005) found benefits of aerobic activity, 3 months of resistance training was also associated with increased ratings on a QoL mental health subscale (Kimura et al 2010). However, Oken et al (2006) found that a group of elderly adults who performed yoga once a week for 6 months showed increased QoL ratings whereas a walking group did not. This suggests that some types of physical activity may be more strongly associated with QoL than others, perhaps due to intensity or specific characteristics, such as whether it is a social activity or not. On the other hand, a review of the literature found consistent increases in QoL as a result of physical activity, regardless of the type (Rejeski and Mihalko 2001). The social interaction and mental stimulation a participant receives while taking part in an intervention study may contribute more to QoL than does the physical activity. The first aim of this study was therefore to examine whether different types of physical activity are associated with self-rated QoL within a large, community-based, observational study.

The second aim of this study was to identify other factors that may contribute to the relationship between physical activity and QoL. Instrumental Activities of Daily Living (IADL) may at least partially mediate the relationship between physical activity and QoL. Increased muscle strength and flexibility that come from regular physical activity may enable individuals to carry out tasks without the need for help from others, thus contributing to QoL ratings. Although physical activity does not appear to reduce disability, reviews of the literature have found that it does lessen 'functional limitations' and increases independence (Keysor 2003, Paterson and Warburton 2010, Spirduso and Cronin 2001). Functional ability and reliance on help from others have also been shown previously to be associated with QoL in the elderly (Andersen et al 2004, Patrick et al 2000, Wlodarczyk et al 2004). The possibility of a relationship between these three factors has been relatively ignored in previous literature, despite the implications of this relationship for clinical practice, and the present study therefore aimed to investigate whether IADL abilities mediate the relationship between physical activity and QoL.

\section{Method}

\section{Participants}

A total of 719 community-dwelling men and women aged 52-98 years were recruited from three sites around Indonesia as part of the Study of Elderly's Memory Impairment and Associated Risk Factors (SEMAR) study, carried out between 2006 and 2009 (described in more detail in Hogervorst et al 2009): Central and South Jakarta $(n=298)$, Borobudur (near
Yogyakarta; $\mathrm{n}=214$ ), and Citengah (near Bandung; $\mathrm{n}=207$ ). Local residents and those in surrounding villages were given information about the study by village elders or staff at local community centres and care homes. Participants were tested at their local community centre $(n=667)$ or care home $(n=49)$ where possible. Participants with limited mobility were tested at home $(n=3)$. Written informed consent was gained from all participants before study onset and, if participants brought a carer with them, they too signed a consent form. Appropriate measures (assignment of participant ID, secure storage of data, etcetera) were taken to ensure anonymity and confidentiality of the data. Ethical approval was obtained from the universities involved prior to study onset, as were governmental and local permits.

\section{Measures and procedure}

Participants were asked to complete an extensive questionnaire to provide information on demographic characteristics and lifestyle behaviours, aided by trained research assistants at community health centres. This questionnaire was developed specifically to assess lifestyle behaviours in Indonesia (and contained items relating to participation in a range of physical, social, and mental activities. Forward- and backtranslations (English and Indonesian) were completed prior to study onset to ensure that the questionnaire maintained its intended meanings, and a native speaker administered all questions verbally. Physical activity variables included on the questionnaire were sport, walking, gymnastics, and gardening. The term 'sport' included a range of activities (tennis, cycling, running, badminton, gym, calisthenics, swimming, tai chi, and other general fitness classes in the community). Sport, gymnastics, and gardening were scored as dichotomous 'yes' or 'no' responses. Walking was scaled on a 5-point Likert scale to provide increased variability in responses to this measure. IADL were assessed using the Lawton scale (Lawton and Brody 1969), which rates an individual's ability to perform the activities (as shown in Table 1). Higher scores indicate more independence and less reliance on help from others.

Health-related QoL was assessed using the Medical Outcome Survey Short Form-36 questionnaire (SF-36; Ware and Sherbourne 1992). This questionnaire consists of 36 questions about the respondent's health and physical pain as well as how their health restricts their daily activities. The physical functioning and role physical dimensions were removed to avoid circular reasoning, leaving six dimensions in the final rating. Participants' responses to each dimension were standardised to a $0-100$ point scale and were averaged to create a total score. Large United Kingdom (UK) population studies suggest that the SF-36 has high internal consistency (Brazier et al 1992, Jenkinson et al 1993) and high construct validity, with significant differences in SF-36 scores between those who report recent illness and those who do not (Jenkinson et al 1993, Lyons et al 1994).

This was a cross-sectional study examining the relationship between self-reported frequency of participation in different types of physical activity and scores on the SF-36 while adjusting for age in years (as QoL has been seen to 
Table 1. List of Independent Activities of Daily Living (IADL) included in the study

Independent Activities of Daily Living (IADL)

Extending message/using telephone

Shopping

Preparing meal

Housekeeping

Washing clothes

Utilization of transportation means

Preparing own medication

Ability to handle finances

decline with age [Ho et al 2007]). Years of education completed and smoking status were also included as covariates that may reflect on QoL. The IADL score was included as a mediating variable between physical activity and QoL. Weight was not available for these analyses but will be included in follow-up analyses of a smaller subset. Alcohol consumption was considered as a covariate but, as most were of Muslim faith, no participants reported drinking alcohol.

\section{Statistical analysis}

Hierarchical regression was used to examine the relationship between different types of physical activity and SF-36 scores while controlling for the selected covariates. Covariates (age, education and smoking status) were added as a block in Step 1, with the physical activity variables being added as a block in Step 2. IADL scores were added at Step 3 to examine whether they accounted for any of the relationship between physical activity and SF-36 scores. Variables were added in these steps, using the Enter method. As walking frequency was scored on a Likert scale, coding was used to transform the variable into four separate dummy variables (each with two levels) by contrasting each level of walking with the previous level (for example, 'often' versus 'sometimes'). These new dummy variables were then put into the regression model in the same step (Stockburger n.d.). Analysis of residuals revealed no violation of normality or presence of outliers and multicollinearity was not suspected as no high correlations were seen between predictor variables. Analyses were carried out in SPSS v. 18.0 statistical analysis software, with a required alpha value of $<.05$.

\section{Findings}

Of the original 719 participants, complete data sets were available for 677. Participants had a mean age of 69.2 years (SD 7.7 years) and 434 (64.1\%) of the participants were women. SF-36 total scores ranged from 0 to 99 with a mean of 77.9 (SD 15.7). IADL scores ranged from 0 to 16 with a mean of 13.3 (SD 3.9). Approximately $43 \%(n=311)$ of respondents reported participating in sport, and $14 \%(\mathrm{n}=100)$ reported participating in gardening. Sixty-three percent ( $n=447$ ) of respondents reported walking 'often' or 'very often'. A low numbers of participants responded 'yes' to participation in gymnastics $(n=10)$; this activity was removed from the analysis due to insufficient variability in responses. Table 2 shows the Pearson correlations between each of the independent variables and SF-36 scores. Participation in walking and sport were both significantly correlated with SF-36 scores $(\mathrm{r}=.306$ and $\mathrm{r}=.169$ respectively), with those participating in more physical activity showing higher SF-36 scores. IADL scores showed a significant positive correlation with SF-36 scores $(r=.354)$ and walking $(r=.238)$.

Table 3 shows the standardized beta values and significance levels for each variable at each step of the regression

Table 3. Standardized beta values of each variable and $R^{2}$ and $F$ values at each step of the regression analysis

\begin{tabular}{lccc}
\hline Variable & Step 1 & Step 2 & Step 3 \\
\hline Age & $-.137^{* *}$ & $-.075^{*}$ & .048 \\
Education & $.227^{* *}$ & $.210^{* *}$ & $.189^{* *}$ \\
Smoking & -.026 & -.030 & -.021 \\
Walking seldom & & $.505^{* *}$ & $.285^{* *}$ \\
Walking sometimes & & $.922^{* *}$ & $.591^{* *}$ \\
Walking often & & $.983^{* *}$ & $.622^{* *}$ \\
Walking very often & & $.397^{* *}$ & $.267^{* *}$ \\
Sport & & $-.022^{*}$ & -.052 \\
Gardening & & -.005 & -.022 \\
IADL & & & $.371^{* *}$ \\
R2 & .081 & .186 & .280 \\
R2 change & $.081^{* *}$ & $.105^{* *}$ & $.095^{* *}$ \\
\hline
\end{tabular}

Note: Dependent variable: Medical Outcome Survey Short Form-36 scores Abbreviations: IADL - Instrumental Activities of Daily Living

*significant at the $p<.05$ level; ** significant at the $p<.001$ level

Table 2. Pearson correlations between walking and selected covariates

\begin{tabular}{|c|c|c|c|c|c|c|c|}
\hline & Walking & Sport & Gardening & Age & Education & Smoking & IADL score \\
\hline Walking & 1 & & & & & & \\
\hline Sport & $.249^{* *}$ & 1 & & & & & \\
\hline Gardening & $.140^{* *}$ & .070 & 1 & & & & \\
\hline Age & $-.202^{* *}$ & $-.188^{* *}$ & -.066 & 1 & & & \\
\hline Education & $.174^{* *}$ & $.540 * *$ & $.087^{\star}$ & $-.158^{* *}$ & 1 & & \\
\hline Smoking & -.071 & $-.196^{* *}$ & $.081^{*}$ & .049 & -.012 & 1 & \\
\hline IADL score & $.238^{* *}$ & .014 & .069 & $-.284^{* *}$ & .001 & .012 & 1 \\
\hline SF-36 score & $.306^{* *}$ & $.169^{\star *}$ & .038 & $-.142^{* *}$ & $.246^{* *}$ & -.049 & $.354^{* *}$ \\
\hline
\end{tabular}

Note: Abbreviations: IADL - Instrumental Activities of Daily Living; SF-36 - Medical Outcome Survey Short Form-36

${ }^{*}$ significant at the $p<.05$ level; ** significant at the $p<.001$ level 
Fig. 1. Error bar chart of walking frequencies and Quality of Life ratings.

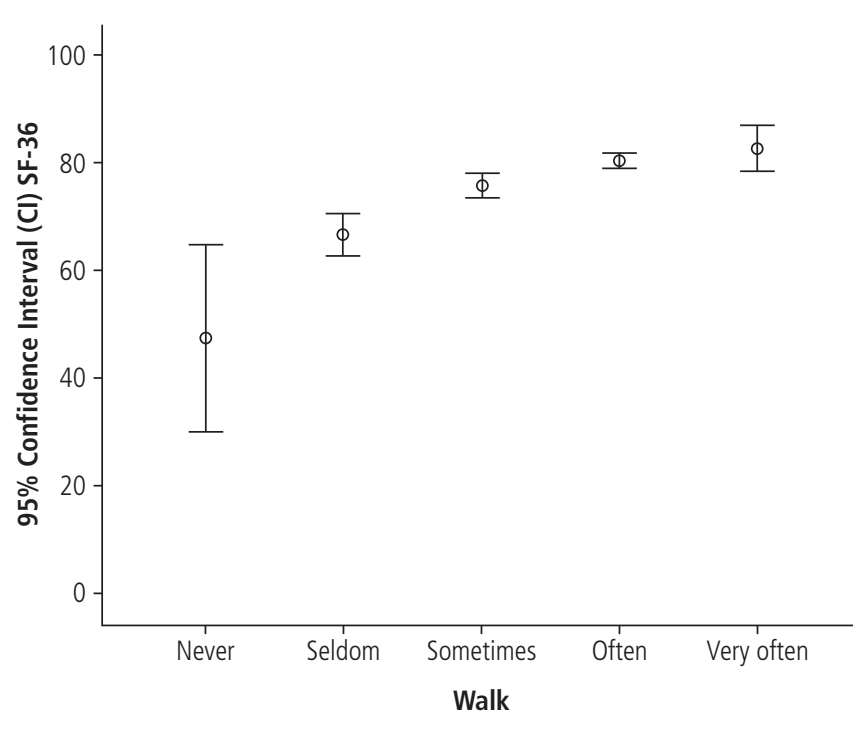

model, as well as changes in $\mathrm{R}^{2}$. After accounting for age, education and smoking status, physical activity explained $10 \%$ of the variance in SF-36 scores. Of the three physical activities, only walking uniquely and significantly contributed to the model. After adjustment for IADL scores (which independently explained a further $9.5 \%$ of the variance in SF-36 scores, $\mathrm{p}=.000$ ), the strength of the association between walking and higher SF-36 scores was reduced slightly but remained significant (see Fig. 1). The relationship between walking and SF-36 scores was therefore mostly independent of IADL. Standardised beta values revealed that the individual contributions of walking and IADL scores to SF-36 scores were comparable. Education also explained a significant amount of the variance in SF-36 scores in all steps of the regression model, while age was not a significant predictor after adjustment for IADL scores.

A compound score that included frequency of participation in all of the physical activities was not significant in another regression model (data not shown). When data were stratified by sex, similar results were found for men and women. Stratifying the sample by district also revealed no differences in the relationship of walking and SF-36 scores between those living in rural and those living in urban areas.

\section{Discussion and limitations}

The aims of this study were to investigate whether different types of physical activity were associated with QoL in an older, community-based sample and whether increased IADL abilities mediated this relationship. This study found a strong association between frequency of walking and higher QoL ratings, while participating in sport or gardening was not associated with QoL. IADL were strongly associated with higher QoL ratings and they partially explained the association between walking and QoL. However, much of the relationship between walking and QoL was independent of IADL abilities. These findings were unaffected by participant gender or area of residence.

The lack of an association of QoL with sport and gardening may be due to using dichotomous measurement of participation offering too little variation in scores, but it may also indicate a confounding influence of other variables such as education, which was correlated with QoL ratings in this study. Glasgow et al (1997) observed higher ratings on the SF-20 in those with increased years of education among a large sample of middle-aged diabetes patients. Education may be linked to better access to services or awareness of seeking health advice and support, or even taking preventative measures against serious illness or injury. On further investigation, those who reported gardening were mostly farmers, a lifestyle possibly associated with physical strain, possible injury, and low socioeconomic status that might confound the association with QoL. These findings might be especially pertinent to Indonesia and similar cultures and it is unclear how well these findings translate to those living in other areas where different physical activities are associated with different lifestyles. Future research in this area should thus consider low education as a risk factor for low QoL and its associated outcomes.

Stewart et al (2003) showed that higher fitness as measured by $\mathrm{VO}_{2} \max$ (maximum oxygen uptake, one measure to measure the capacity to perform sustained aerobic effort) and weight was associated with increased QoL ratings. Measures of intensity were not included in this study but it is possible that high intensity sport leading to higher fitness would show quantitatively or qualitatively different effects on QoL than would light exercise (Rennemark et al 2009). For this study it was not possible to examine the effect of participation in individual sports, and the lack of a relationship with QoL being due to participants in this sample only engaging in low intensity activity cannot be ruled out. It should also be noted that the physical activity scales are based upon subjective ratings and are thus vulnerable to self-serving bias and inaccuracies (the Lawson scale of IADL shares these weaknesses). Objective measures of physical activity, such as accelerometer readings, are thus recommended in future work to help lessen these limitations and help better compare the impact of different types of physical activity.

The benefits to QoL of walking may be due to stress reduction, social or cognitive stimulation, changes in overall health, or a combination of these and other factors. Walking may thus be recommended to the older age community by occupational health advisors as a convenient and accessible activity to act as a buffer against long recovery times in the event of illness or disability. IADL are often targeted during occupational therapy and it is important to note that there was a strong association between IADL and QoL ratings in our study. While walking should not be taken as an alternative to standard care, these findings suggest that incorporating additional walking activities as part of treatment programmes may contribute to QoL and thus treatment outcomes. 
These conclusions and implications are cautionary since this was an observational study with limited information regarding participation in a wide range of different types of physical activity. It is therefore difficult to establish a causal relationship between physical activity and QoL without completing controlled studies. Indeed, these findings are contrary to Oken et al's (2006) intervention study that found no association between walking and QoL. Only relatively healthy adults were included in their study with participants suffering from conditions such as diabetes, uncontrolled hypertension, and significant vascular disease being excluded from participating. We made no exclusions in relation to health, and IADL scores indicated a range of ability with no participants showing complete independence on the Lawton scale. However, few individuals in this community sample showed severe disability. Future research should thus consider this relationship in those with greater levels of dependence to determine the effectiveness of walking as an intervention for these groups.

\section{Conclusions}

In summary, participation in walking is associated with higher QoL ratings in this elderly South East Asian cohort, and this relationship is independent of IADL and education. Further evidence of a causal relationship would indicate that walking in addition to standard IADL-targeted treatment may be useful for health promotion and treatment outcomes, thus having wide reaching clinical benefits to a range of population groups. The role of fitness and other potential mediating and moderating variables (such as culture) should be further investigated to strengthen healthcare advice. Despite methodological limitations, this study provides evidence of a relationship between physical activity and QoL independent of IADL and future controlled studies should aim to examine the nature of this relationship and its impact on health outcomes both in the community and in a therapeutic setting.

\section{Key findings}

- Walking is associated with quality of life independently of IADL abilities.

\section{What the study has added}

This large community-based study highlights the potential importance of physical activity to occupational health treatment programmes.

\section{Conflict of interest: None declared.}

Funding: This research received no specific grant support from any funding agency in the public, commercial, or not-for-profit sectors.

Research ethics: Ethics approval was not required for this study.

\section{References}

Acree LS, Longfors J, Fjeldstad AS, Fjeldstad C, Schank C, Nickel KJ, ... Gardner AW (2006) Physical activity is related to quality of life in older adults. Health and Quality of Life Outcomes, 4(37). doi:10.1186/1477-7525-4-37
Andersen CK, Wittrup-Jensen KU, Lolk A, Andersen K, Kragh-Sørensen P (2004) Ability to perform activities of daily living is the main factor affecting quality of life in patients with dementia. Health Quality of Life Outcomes, 2(52). doi:10.1186/1477-7525-2-52

Antunes HK, Stella SG, Santos RF, Bueno OF, de Mello MT (2005) Depression, anxiety and quality of life scores in seniors after an endurance exercise program. Revista Brasileira de Psiquiatria, 27(4), 266-271.

Brazier JE, Harper R, Jones NM, O'Cathain A, Thomas KJ, Usherwood T, Westlake $L$ (1992) Validating the SF-36 health survey questionnaire: new outcome measure for primary care. British Medical Journal, 305(6846), 160-164.

Cakar E, Dincer U, Kiralp MZ, Cakar DB, Durmus O, Kilac H, ... Alper C (2010) Jumping combined exercise programs reduce fall risk and improve balance and life quality of elderly people who live in a long-term care facility. European Journal of Physical and Rehabilitation Medicine, 46(1), 59-67.

Clifford A, Bandelow S, Hogervorst E (2009) The effects of physical exercise on cognitive function in the elderly: a review. In: Q Gariépy, R Ménard, ed. Handbook of cognitive aging: causes, processes and effects. New York: Nova Science Publishers. 109-150.

Dorr DA, Jones SS, Burns L, Donnelly SM, Brunker CP, Wilcox A, Clayton PD (2006) Use of health-related, quality-of-life metrics to predict mortality and hospitalizations in community-dwelling seniors. Journal of the American Geriatrics Society, 54(4), 667-673.

Efficace F, Bottomley A, Coens C, Van Steen K, Conroy T, Schöffski P, ... Köhne CH (2006) Does a patient's self-reported health-related quality of life predict survival beyond key biomedical data in advanced colorectal cancer? European Journal of Cancer, 42(1), 42-49.

Fallowfield L (2009) What is Quality of Life? What is...? London: Hayward Medical Communications. Available at: $h$ ttp://www.medicine.ox.ac.uk/ bandolier/painres/download/whatis/WhatisQOL.pdf Accessed 15.01.11.

Glasgow RE, Ruggiero L, Eakin EG, Dryfoos J, Chobanian L (1997) Quality of life and associated characteristics in a large national sample of adults with diabetes. Diabetes Care, 20(4), 562-567.

Hennessy CH, Moriarty DG, Zack MM, Scherr PA, Brackbill R (1994) Measuring health-related quality of life for public health surveillance. Public Health Reports, 109(5), 665-672.

Ho TJ, Liang WM, Lien CH, Ma TC, Kuo HW, Chu BC, ... Lin JG (2007) Health-related quality of life in the elderly practicing T'ai Chi Chuan. Journal of Alternative Complementary Medicine, 13(10), 1077-1083.

Hogervorst E, Sadjimim T, Yesufu A, Kreager P, Rahardjo TB (2008) High tofu intake is associated with worse memory in elderly Indonesian men and women. Dementia and Geriatric Cognitive Disorders, 26(1), 50-57.

Houde SC, Melillo KD (2002) Cardiovascular health and physical activity in older adults: an integrative review of research methodology and results. Journal of Advanced Nursing, 38(3), 219-234.

Jenkinson C, Coulter A, Wright L (1993) Short form 36 (SF36) health survey questionnaire: normative data for adults of working age. British Medical Journal, 306(6890), 1437-1440

Keysor JJ (2003) Does late-life physical activity or exercise prevent or minimize disablement? A critical review of the scientific evidence. American Journal of Preventative Medicine, 25(3 Suppl 2), 129-136.

Kimura K, Obuchi S, Arai T, Nagasawa H, Shiba Y, Watanabe S, Kojima M (2010) The influence of short-term strength training on health-related quality of life and executive cognitive function. Journal of Physiological Anthropology, 29(3), 95-101.

Lawton MP, Brody EM (1969). Assessment of older people: self-maintaining and instrumental activities of daily living. The Gerontologist, 9(3), 179-186. 
Lyons RA, Perry HM, Littlepage BN (1994) Evidence for the validity of the Short-form 36 questionnaire (SF-36) in an elderly population. Age and Ageing, 23(3), 182-184.

Mapes DL, Lopes AA, Satayathum S, McCullough KP, Goodkin DA, Locatelli F, ... Port FK (2003) Health-related quality of life as a predictor of mortality and hospitalization: the Dialysis Outcomes and Practice Patterns Study (DOPPS). Kidney International, 64(1), 339-349.

Oken BS, Zajdel D, Kishiyama S, Flegal K, Dehen C, Haas M, Leyva J (2006) Randomized, controlled, six-month trial of yoga in healthy seniors: effects on cognition and quality of life. Alternative Therapies in Health and Medicine, 12(1), 40-47.

Paterson DH, Warburton DER (2010) Physical activity and functional limitations in older adults: a systematic review related to Canada's Physical Activity Guidelines. International Journal of Behavioural Nutrition and Physical Activity, 7(38). doi:10.1186/1479-5868-7-38

Patrick DL, Kinnea S, Engelberg RA, Pearlman RA (2000) Functional status and perceived quality of life in adults with and without chronic conditions. Journal of Clinical Epidemiology, 53(8), 779-785.

Rejeski WJ, Mihalko SL (2001) Physical activity and quality of life in older adults. Journals of Gerontology, 56A(Special Issue 11), 23-35.

Rennemark M, Lindwall M, Halling A, Berglundd J (2009) Relationships between physical activity and perceived qualities of life in old age. Results of the SNAC study. Aging \& Mental Health, 13(1), 1-8.
Spirduso WW, Cronin DL (2001) Exercise dose-response effects on quality of life and independent living in older adults. Medicine and Science in Sports and Exercise, 33(6 Suppl), S598-S608.

Stewart KJ, Turner KL, Bacher AC, DeRegis JR, Sung J, Tayback M, Ouyang P (2003) Are fitness, activity, and fatness associated with health related quality of life and mood in older persons? Journal of Cardiopulmonary Rehabilitation, 23(2), 115-121.

Stockburger DW (n.d.) Multiple regression with categorical predictor variables. In: DW Stockburger. Multivariate statistics: concepts, models and applications. Available at: http://www.psychstat.missouristate.edu/ multibook/mlt08m.html Accessed 03.08.10.

Van der Bij AK, Laurant MG, Wensing M (2002) Effectiveness of physical activity interventions for older adults: a review. American Journal of Preventative Medicine, 22(2), 120-133.

Ware JE, Sherbourne CD (1992) The MOS 36-item short-form health survey (SF-36). I. Conceptual framework and item selection. Medical Care, 30(6), 473-483.

Wlodarczyk JH, Brodaty H, Hawthorne G (2004) The relationship between quality of life, Mini-Mental State Examination, and the Instrumental Activities of Daily Living in patients with Alzheimer's disease. Archives of Gerontology and Geriatrics, 39(1), 25-33.

World Health Organization (2011) World health statistics 2011. Switzerland: WHO. Available at: $h$ ttp://www.who.int/whosis/whostat/EN_WHS2011_Full.pdf Accessed 02.02.12. 